\title{
Synthesis of a New Calix[4]Arene and Its Application in Construction of a Highly Selective Silver Ion-Selective Membrane Electrode
}

\author{
Saeed Taghvaei-Ganjali, ${ }^{1}$ Reza Zadmard, ${ }^{2}$ Masoumeh Zeyaei, ${ }^{1}$ Kabeh Rahnama, ${ }^{1}$ \\ Farnoush Faridbod, ${ }^{3}$ and Mohammad Reza Ganjali ${ }^{3}$ \\ ${ }^{1}$ Department of Chemistry, Islamic Azad University, North Tehran Branch, P.O. Box 19585-936, Tehran, Iran \\ ${ }^{2}$ Chemistry and Chemical Engineering Research Center of Iran, P.O. Box 14335-186, Tehran, Iran \\ ${ }^{3}$ Center of Excellence in Electrochemistry, Faculty of Chemistry, University of Tehran, P.O. Box 14155-6455, Tehran, Iran
}

Correspondence should be addressed to Saeed Taghvaei-Ganjali, taghvaei@hotmail.com

Received 14 April 2009; Accepted 17 June 2009

Recommended by Cyril Parkanyi

\begin{abstract}
A PVC membrane sensor for Ag (I) ions has been prepared. The membrane has 5, 11, 17, 23-tetra-tert-butyl-25-(3-N, Ndiethyldithio carbamoylpropoxy)-26,27,28-tris-propoxy calix[4] arene (CAD) as a carrier. It was found that the sensor exhibits a Nernstian response for $\mathrm{Ag}^{+}$ions over a wide concentration range $\left(10^{-2}-10^{-6} \mathrm{M}\right)$. Additionally, it illustrates a fast response time (about 5 seconds), and it can be used for at least 2 months without any considerable divergence in potentials. The nature of the plasticizer, the additive, the concentration of internal solutions in the electrodes, and the composition of the membrane were investigated. Furthermore, the suggested membrane electrode revealed good selectivities for $\mathrm{Ag}^{+}$over a variety of other metal cations, and it could be used in the $\mathrm{pH}$ range of 3.0-7.0. Eventually, it was successfully applied as an indicator electrode for the potentiometric titration of $\mathrm{Ag}^{+}$ion with $\mathrm{NaCl}$.
\end{abstract}

Copyright (c) 2009 Saeed Taghvaei-Ganjali et al. This is an open access article distributed under the Creative Commons Attribution License, which permits unrestricted use, distribution, and reproduction in any medium, provided the original work is properly cited.

\section{Introduction}

A vast ranges of chemically, clinically, or environmentally important analytes are now routinely monitored, using ion-selective electrodes based on impregnated polymeric membranes [1-3]. During the past two decades, an extensive effort has taken place in the synthesis and characterization of neutral ionophores with high selectivity for specific metal ions in order to develop new potentiometric and optical sensors for the determination of the respective metal ions in different real samples [4-7]. In recent years, several neutral carriers have been used in the PVC electrode membrane studies of some transition and heavy metal ions [8-15]. In this paper, the use of 5,11, 17, 23-tetra-tert-butyl-25(3-N, N-diethyldithio carbamoylpropoxy)-26, 27, 28-trispropoxy calix[4]arene is reported as an excellent neutral carrier in the construction of a highly selective silver PVCbased membrane electrode.

\section{Experimental Section}

2.1. Ionophore Synthesis. The ionophore 5, 11, 17, 23-tetratert-butyl-25-(3-N, N-diethyldithio carbamoylpropoxy)-26, 27, 28-tris-propoxy calix[4]arene (3) was synthesized in three steps according to the following (Scheme 1).

2.2. Electromotive Force (EMF) Measurements. All EMF measurements were carried out with the following assembly: $\mathrm{Ag}-\mathrm{AgCl} /\left(1.0 \times 10^{3-} \mathrm{M} \mathrm{Ag} \mathrm{NO}{ }_{3}\right) / \mathrm{PVC}$ Membrane/sample solution $/ \mathrm{Hg}-\mathrm{Hg}_{2} \mathrm{Cl}_{2}, \mathrm{KCl}$ (satd.). A corning ion analyzer with a $250 \mathrm{pH} / \mathrm{mV}$ meter was used for the potential measurements at $25.0 \pm 0.1^{\circ} \mathrm{C}$. The EMF observations were made with the aid of a double-junction saturated calomel electrode (SCE, Philips) with the chamber filled with an ammonium nitrate solution. The activities were calculated according to the Debye-Hückle procedure [16]. 


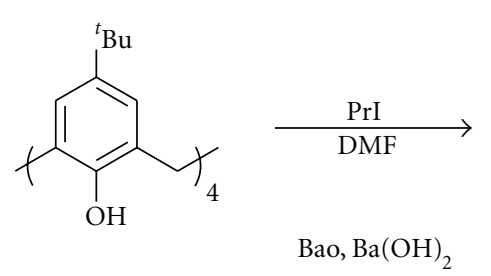<smiles>CCNC(=S)[Te]</smiles><smiles>CCCc1cc(Br)cc(CCc2cc(Br)cc(CC)c2OCC)c1O</smiles>

1<smiles>CCCOc1c(C)cc(CCc2ccccc2)cc1Cc1cc(CC(C)(C)C)cc(C(C)(C)C)c1OCCCSC(=S)N(CC)CC</smiles>

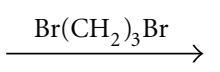<smiles>CCCOc1c(CCc2cc(CCC)cc(CCc3ccccc3)c2OCCCBr)cc(Br)cc1C(C)C</smiles>

Scheme 1: Synthetic route of 3.

\section{Results and Discussion}

To the best of our knowledge, there is no report on the CAD complexes stability with metal ions. Thus, the CAD complexation with a soft donor atom and some transition and heavy metal ions as soft ions was investigated, conductometrically in acetonitrile solution at $25 \pm 0.05^{\circ} \mathrm{C}$ $[8,9]$ in order to obtain a clue about the stability and the selectivity of the resulting complexes. In all cases, the results, presented that the ligand to cation mole ratio is 1 , indicating the formation of stable $1: 1$ complexes between CAD and the used cations. The formation constant, $\mathrm{K}_{\mathrm{f}}$, of the resulting 1 : 1 complexes was evaluated by computer fitting of the molar conductance-mole ratio data to appropriate equations $[8,9]$. The stability of the resulting complexes varies the order $\mathrm{Ag}>\mathrm{Tl}>\mathrm{Fe}^{3}>\mathrm{K}>\mathrm{Mg}^{2+}>\mathrm{Ni}^{2} \sim \mathrm{Co}^{2+} \sim \mathrm{Cu}^{2+} \sim$ $\mathrm{Zn}^{2+} \sim \mathrm{Na}^{+} \sim \mathrm{Ca}^{2+}$. As a consequence, CAD may be used as a suitable ionophore for the silver membrane sensor.

In preliminary experiments, it was used to prepare the PVC membrane ion-selective electrodes for a range of cations, including alkali, alkaline earth, and transition metal ions. The potential responses of these sensors are listed in Figure 1. With the exception of $\mathrm{Ag}^{+}$, the slope of the corresponding potential-pM plots is lower than the expected Nernstian slope of 59 and $29 \mathrm{mV}$ per decade for univalent and bivalent cations, respectively.

Generally, the sensitivity and the selectivity of the ionselective electrodes depend not only on the nature and the amount of the applied ionophore but also significantly on the membrane composition, the plasticizer nature, and the amount of lipophilic additives. The effects of the above mentioned factors on the potential response of the $\mathrm{Ag}^{+}$sensor were investigated. The concluding data are summarized in Table 1. It is obvious that, of three different used solvent mediators, $61 \%$ DBP or $61 \%$ BA in the presence of $5 \%$ ionophore and $4 \%$ sodium tetraphenyl borate (numbers 9 and 7 , resp.) resulted in the best sensitivity with a Nernstian and near-Nernstian slopes of $59.7 \pm 0.4$ and $56.7 \pm$ $0.5 \mathrm{mV} /$ decade, respectively. Due to the large size and low charge density of the $\mathrm{Ag}^{+}$ion, using a plasticizers with low polarity like DBP or BA which have lower polarity than $\mathrm{NB}$, for better extraction of $\mathrm{Ag}^{+}$ion, results in the best responses. Data on Table 1 also shows that, in the absence of ionophore in the membrane, the slope of the sensor is very poor (number 11 with a slope $7.8 \pm 0.5 \mathrm{mV} /$ decade).

The responses of the membranes based on different amounts of ionophore were also investigated, and the results are given in Table 1. As it can be seen, the membrane containing $5 \%$ of ionophore shows a Nernstian response (number 9 with a slope of $59.7 \pm 0.4 \mathrm{mV} /$ decade).

The effects of the amounts of the additive on the sensivity of the sensor were also tested. Table 1 revealed that addition of $4 \% \mathrm{NaTPB}$ will increase the sensitivity of the electrode response considerably from $21.2 \pm 0.4$ to $59.7 \pm 0.4 \mathrm{mV} /$ decade (number 2 to number 9 ). It should be noted that the presence of lipophilic anions in the cation-selective membrane electrodes reduces the ohmic resistance [10] and enhances response behavior and selectivity [11], but also, in cases where the extraction ability of the membrane is poor, it increases the electrode sensitivity [12].

However, the membrane number 9 with the composition of $61 \%$ DBP, $5 \%$ CAD, $4 \%$ NaTPB, and 30\% PVC results in the best response. 
TABLE 1: Optimization of membrane ingredients.

\begin{tabular}{|c|c|c|c|c|c|}
\hline \multirow{2}{*}{ Membrane no. } & \multicolumn{4}{|c|}{ Composition (\%) } & \multirow{2}{*}{ Slope ( $\mathrm{mV}$ per decade) } \\
\hline & PVC & Plasticizer & Ionophore & NaTPB & \\
\hline 1 & 30 & BA, 66 & 4 & - & $17.5 \pm 0.5$ \\
\hline 2 & 30 & BA, 65 & 5 & - & $21.2 \pm 0.4$ \\
\hline 3 & 30 & BA, 64 & 6 & - & $20.3 \pm 0.3$ \\
\hline 4 & 30 & BA, 63 & 7 & - & $19.2 \pm 0.6$ \\
\hline 5 & 30 & BA, 63 & 5 & 2 & $48.4 \pm 0.3$ \\
\hline 6 & 30 & BA, 62 & 5 & 3 & $52.5 \pm 0.3$ \\
\hline 7 & 30 & $\mathrm{BA}, 61$ & 5 & 4 & $56.7 \pm 0.5$ \\
\hline 8 & 30 & $\mathrm{BA}, 60$ & 5 & 5 & $56.4 \pm 0.5$ \\
\hline 9 & 30 & DBP, 61 & 5 & 4 & $59.7 \pm 0.4$ \\
\hline 10 & 30 & $\mathrm{NB}, 61$ & 5 & 4 & $20.8 \pm 0.5$ \\
\hline 11 & 30 & DBP, 66 & - & 4 & $7.8 \pm 0.5$ \\
\hline
\end{tabular}

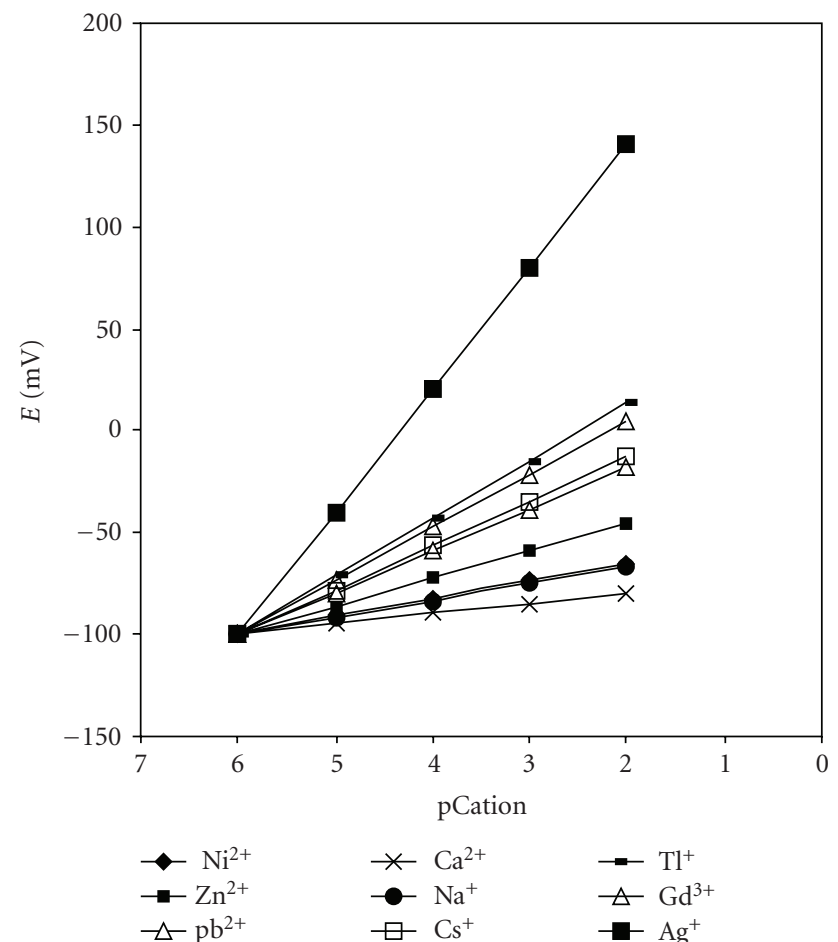

Figure 1: Potential responses of various ion-selective electrodes based on $\mathrm{CAD}, \mathrm{Ni}^{2+}, \mathrm{Ag}^{+}, \mathrm{Ca}^{2+}, \mathrm{Na}^{+}, \mathrm{Cs}^{+}, \mathrm{Gd}^{3+}, \mathrm{Tl}^{+}, \mathrm{Zn}^{2+}, \mathrm{Pb}^{2+}$ with the membrane number 9 .

Moreover, the internal solution concentration $\left(\mathrm{AgNO}_{3}\right)$ in the electrode was changed from $1.0 \times 10^{-3} \mathrm{M}$ to 1.0 $\times 10^{-5} \mathrm{M}$, and the potential response of the $\mathrm{Ag}^{+}$selective electrode was measured. It was found that the concentration variation of the internal solution does not cause any significant difference in the potential response of the electrode, apart from an expected change in the intercept of the resulting Nernstian plot. A $1.0 \times 10^{-3} \mathrm{M}$ concentration of internal solution is quite appropriate for the smooth function of the electrode system.

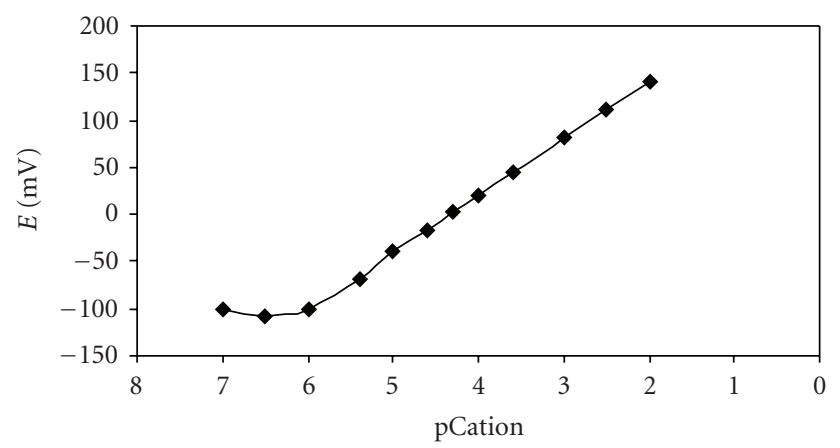

Figure 2: Calibration curve of the silver ion membrane sensor based on CAD with the membrane number 9.

Here it should be mentioned that the critical response characteristics of the $\mathrm{Ag}^{+}$ion-selective electrode were assessed according to the IUPAC recommendation [13]. The electrode demonestrated a linear response to the activity of $\mathrm{Ag}^{+}$ion in the range of $10^{-6}-10^{-2} \mathrm{M}$. Also, the limit of detection was $5.0 \times 10^{-7} \mathrm{M}$, driving from the intersection of the two extrapolated segments of the response potential$\mathrm{pAg}^{+}$plot (Figure 2).

Moreover, the average required time for the $\mathrm{Ag}^{+}$ionselective electrode to reach a potential response was measured. This potential response was accomplished within $\pm 1 \mathrm{mV}$ of the final equilibrium value after successive immersions in a series of nickel ion solutions, each having a 10 -fold difference in concentration. Stable responses were achieved after 5 seconds for concentration $\leq 1.0 \times 10^{-6} \mathrm{M}$. It should be noted that the equilibrium potential essentially remained constant for more than 4 minutes, after which only a slow change was recorded. In addition, the membrane electrodes prepared could be used for at least three months after the preparation without any measurable divergency in their potentials.

On the other hand, the dynamic response time is a considerable factor for the evaluation of any sensors. In this study, the practical response time of the sensors was recorded by changing solutions with different terbium concentrations. 


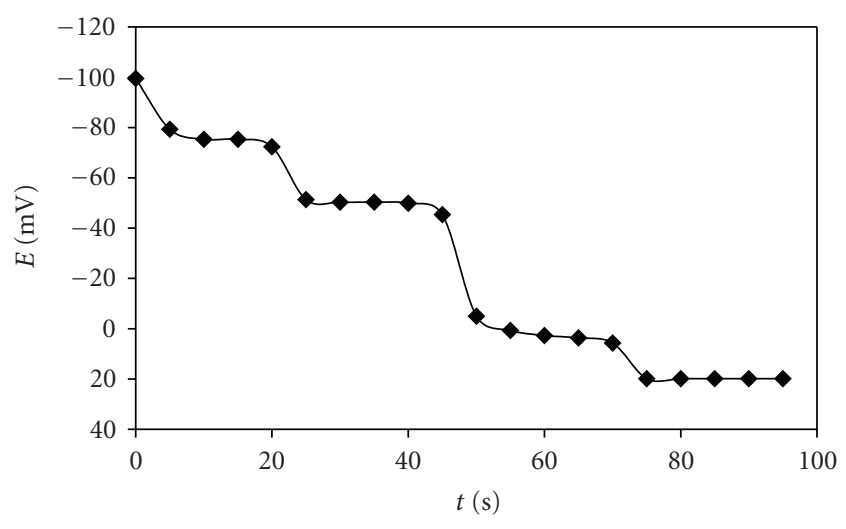

Figure 3: Dynamic response time of the silver sensor for the step changes in the concentration of silver ion: (a) $1.0 \times 10^{-6}$, (b) $1.0 \times$ $10^{-5}$, (c) $1.0 \times 10^{-4}$, and (d) $1.0 \times 10^{-3} \mathrm{M}$.

The measurement sequence was from the lower $(1.0 \times$ $\left.10^{-6} \mathrm{M}\right)$ to the higher $\left(1.0 \times 10^{-2} \mathrm{M}\right)$ concentration. The actual potential versus time traces is depicted in Figure 3. This figure illustrates that the electrode reaches its equilibrium response in a short time of about 5 seconds.

For the description of the interfering ions influence on the response behavior of the ion-selective membrane electrodes, the term of selectivity coefficient, $\left(\mathrm{K}_{\mathrm{A}, \mathrm{B}}\right)$ is usually used. The methods based on the Nicolsky-Eisenman equation for the determination of the potentiometric selectivity coefficient (e.g., the fixed interference method and the mixed solution method) are among the most commonly methods used thus far. However, it has been proved that these methods suffer from limitations regarding the values for ions of unequal charge, the non-Nernstian behavior of interfering ions, and activity dependence of values. Therefore, in this work, the matched potential method (MPM) [14, 15] which is totally independent of the Nicolsky-Eisenman equation, was used to overcome the above-stated difficulties. According to the MPM, a specified activity (concentration) of primary ions (A) is added to a reference solution, and the potential is measured. In another experiment, interfering ions (B) are successively added to an identical reference solution, until the measured potential matches the one obtained before the primary ions addition. Then, the MPM selectivity coefficient is then given by the resulting primary ion to the interfering ion activity (concentration) ratio, $\mathrm{K}_{\mathrm{A}, \mathrm{B}}=\mathrm{a}_{\mathrm{A}} / \mathrm{a}_{\mathrm{B}}$. The experimental conditions employed and the resulting values are summarized in Table 2. From this table it can be concluded that the selectivity coefficients obtained for all the cations were in the order of $5.3 \times 10^{-3}$ or smaller, illustrating that they do not disturb significantly the function of the $\mathrm{Ag}^{+}$ ion-selective electrode.

The influence of $\mathrm{pH}$ of the test solution $\left(1.0 \times 10^{-3} \mathrm{M}\right)$ on the potential response of the $\mathrm{Ag}^{+}$sensor was studied and the resulting data are depicted in Figure 4. In the $\mathrm{pH}$ range of 3.0-7.0, the potential response shows only a slight drift, but at higher $\mathrm{pH}$ values, it greatly diminishes. This is most probably due to the protonation of the nitrogen atoms of ionophore in some extent. In this case, protonated nitrogen

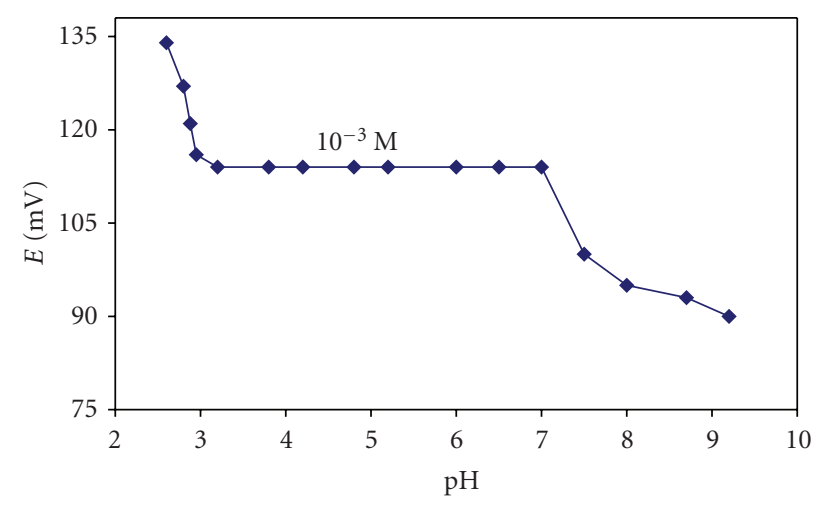

FIGURE 4: Effect of $\mathrm{pH}$ of the test solution on the potential response of the silver ion sensor with the membrane number 9 .

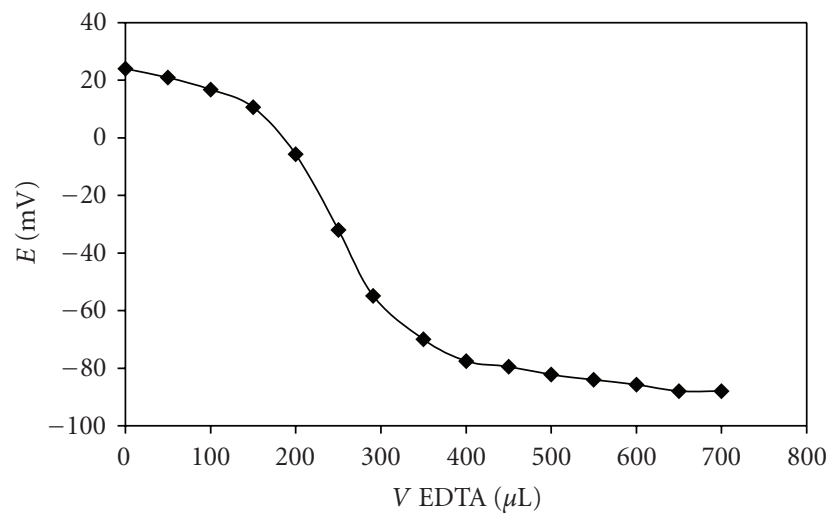

FIGURE 5: Potentiometric titration curve of $25.0 \mathrm{~mL}$ of $1.0 \times 10^{-4} \mathrm{M}$ $\mathrm{Ag}^{+}$solution with a standard solution of $1.0 \times 10^{-2} \mathrm{M}$ of EDTA with the silver sensor as indicator electrode (membrane number 9 ).

TABLE 2: Selectivity coefficients of the silver ion-selective electrode based on CAD.

\begin{tabular}{lc}
\hline Ions & Selectivity coefficients \\
\hline $\mathrm{Ni}^{2+}$ & $6.3 \times 10^{-5}$ \\
$\mathrm{Zn}^{2+}$ & $5.2 \times 10^{-5}$ \\
$\mathrm{Ce}^{3+}$ & $1.1 \times 10^{-5}$ \\
$\mathrm{~Pb}^{2+}$ & $6.3 \times 10^{-4}$ \\
$\mathrm{Na}^{+}$ & $5.4 \times 10^{-5}$ \\
$\mathrm{Ca}^{2+}$ & $4.2 \times 10^{-5}$ \\
$\mathrm{Cs}^{+}$ & $7.5 \times 10^{-5}$ \\
$\mathrm{Tl}^{+}$ & $5.3 \times 10^{-3}$ \\
$\mathrm{Gd}^{3+}$ & $4.2 \times 10^{-4}$ \\
\hline
\end{tabular}

atoms cannot contribute to the interaction of donor atoms of ionophore with silver ions, and so the response of the sensor to silver ions decreases drastically. The main reason for the observed potential drift at the higher $\mathrm{pH}$ values could be due to the responds of the membrane sensor to hydroxyl ions by the deprotonation of $-\mathrm{NH}$ group of the ionophore and decreasing of silver ion concentration in some extent by formation of insoluble $\mathrm{AgOH}$ (with a Ksp of $1.6 \times 10^{-8}$ ). 
Eventually, as far as the practical utility of the proposed membrane sensor is concerned, it was tested with the help of an indicator electrode for the titration of $25.0 \mathrm{~mL}$ of 1.0 $\times 10^{-4} \mathrm{M}$ silver ions with a $1.0 \times 10^{-2} \mathrm{M}$ EDTA solution. The respective results are shown in Figure 5. Obviously, the amount of silver ions in solution can be accurately determined with the electrode.

\section{Acknowledgment}

The authors are grateful to the University of Tehran Research Council for the financial support of this research.

\section{References}

[1] M. E. Mayerhoff and M. N. Opdyche, "Ion-selective electrode," Advances in Clinical Chemistry, vol. 25, p. 1, 1986.

[2] U. Oesch, D. Ammann, and W. Simon, "Ion-selective membrane electrodes for clinical use," Clinical Chemistry, vol. 32, no. 8, pp. 1448-1459, 1986.

[3] G. J. Moody, B. B. Saad, and J. D. R. Thomas, "The development of polymer matrix membranes for ion-selective electrodes," Ion-Selective Electrode Reviews, vol. 10, pp. 71-106, 1988.

[4] D. Ammann, W. E. Morf, P. Anker, P. C. Meier, E. Pretsch, and W. Simon, "Neutral carrier based ion-selective electrodes," Ion-Selective Electrode Reviews, vol. 5, no. 1, pp. 3-92, 1983.

[5] J. Janata, M. Josowitz, and D. M. DeVaney, "Chemical sensors," Analytical Chemistry, vol. 66, no. 12, pp. 207r-228r, 1994.

[6] M. A. Arnold and M. E. Meyerhoff, "Ion-selective electrodes," Analytical Chemistry, vol. 20, pp. 149-154, 1988.

[7] P. Buhlmann, E. Pretsch, and E. Bakker, "Carrier-based ionselective electrodes and bulk optodes. 2. Ionophores for potentiometric and optical sensors," Chemical Reviews, vol. 98, no. 4, pp. 1593-1687, 1998.

[8] M. R. Ganjali, N. Khoshdan, O. R. Hashemi, and S. A. S. Sajjadi, "Thermodynamic study of some pyridinium ion derivatives with 18-crown-6, aza-18-crown-6 and 1,10-diaza18-crown-6 in acetonitrile," Polish Journal of Chemistry, vol. 74, no. 10, pp. 1389-1398, 2000.

[9] M. R. Ganjali, M. H. Zargazi, and A. Mohajeri, "Thermodynamic study of the interaction between some recently synthesized benzo-substituted macrocyclic diamides with some pyridinium ion derivatives in acetonitrile solution," Polish Journal of Chemistry, vol. 75, no. 5, pp. 743-749, 2001.

[10] D. Ammann, E. Pretsch, W. Simon, E. Lindner, A. Bezegh, and E. Pungor, "Lipophilic salts as membrane additives and their influence on the properties of macro- and micro-electrodes based on neutral carriers," Analytica Chimica Acta, vol. 171, pp. 119-129, 1985.

[11] M. Huser, P. M. Gehrig, W. E. Morf, et al., "Membrane technology and dynamic response of ion-selective liquidmembrane electrodes," Analytical Chemistry, vol. 63, no. 14, pp. 1380-1386, 1991.

[12] E. Lindner, E. Gráf, Z. Niegreisz, K. Tóth, E. Pungor, and R. P. Buck, "Responses of site-controlled, plasticized membrane electrodes," Analytical Chemistry, vol. 60, no. 4, pp. 295-301, 1988.

[13] IUPAC Analytical Chemistry Division, Commission on Analytical Nomenclature, "Report: recommendations for nomenclature of ion-selective electrodes," Pure and Applied Chemistry, vol. 48, no. 1, pp. 127-132, 1976.
[14] Y. Umezawa, K. Umezawa, and H. Sato, "Selectivity coefficients for ion-selective electrodes:recommended methods for reporting $K_{A, B}$ pot values," Pure and Applied Chemistry, vol. 67, no. 3, pp. 507-510, 1995.

[15] E. Bakker, "Selectivity of liquid membrane ion-selective electrodes," Electroanalysis, vol. 9, no. 1, pp. 7-12, 1997.

[16] S. Kamata, A. Bhale, Y. Fukunaga, and H. Murata, "Copper(II)-selective electrode using thiuram disulfide neutral carriers," Analytical Chemistry, vol. 60, no. 22, pp. 2464-2467, 1988. 


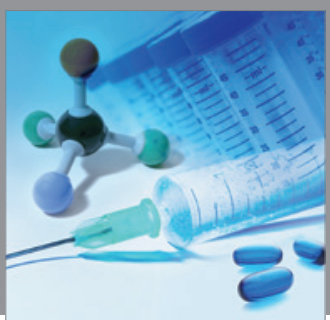

International Journal of

Medicinal Chemistry

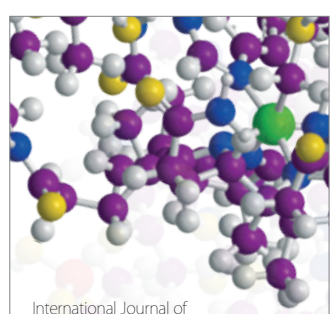

Carbohydrate Chemistry

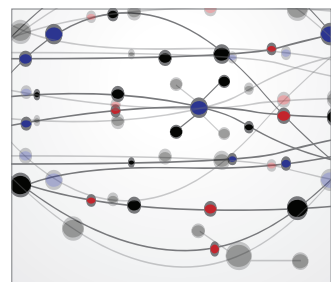

The Scientific World Journal
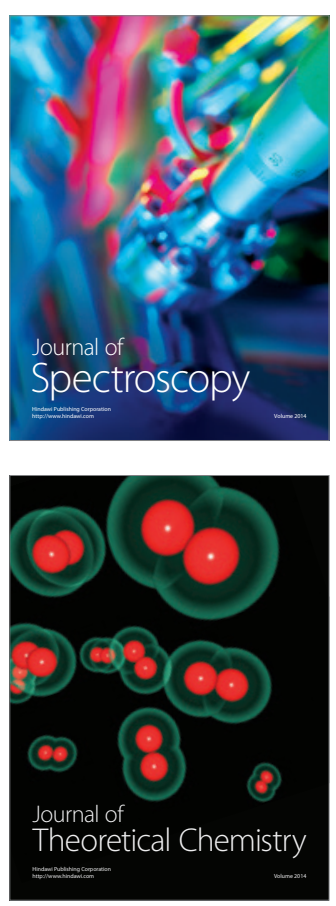
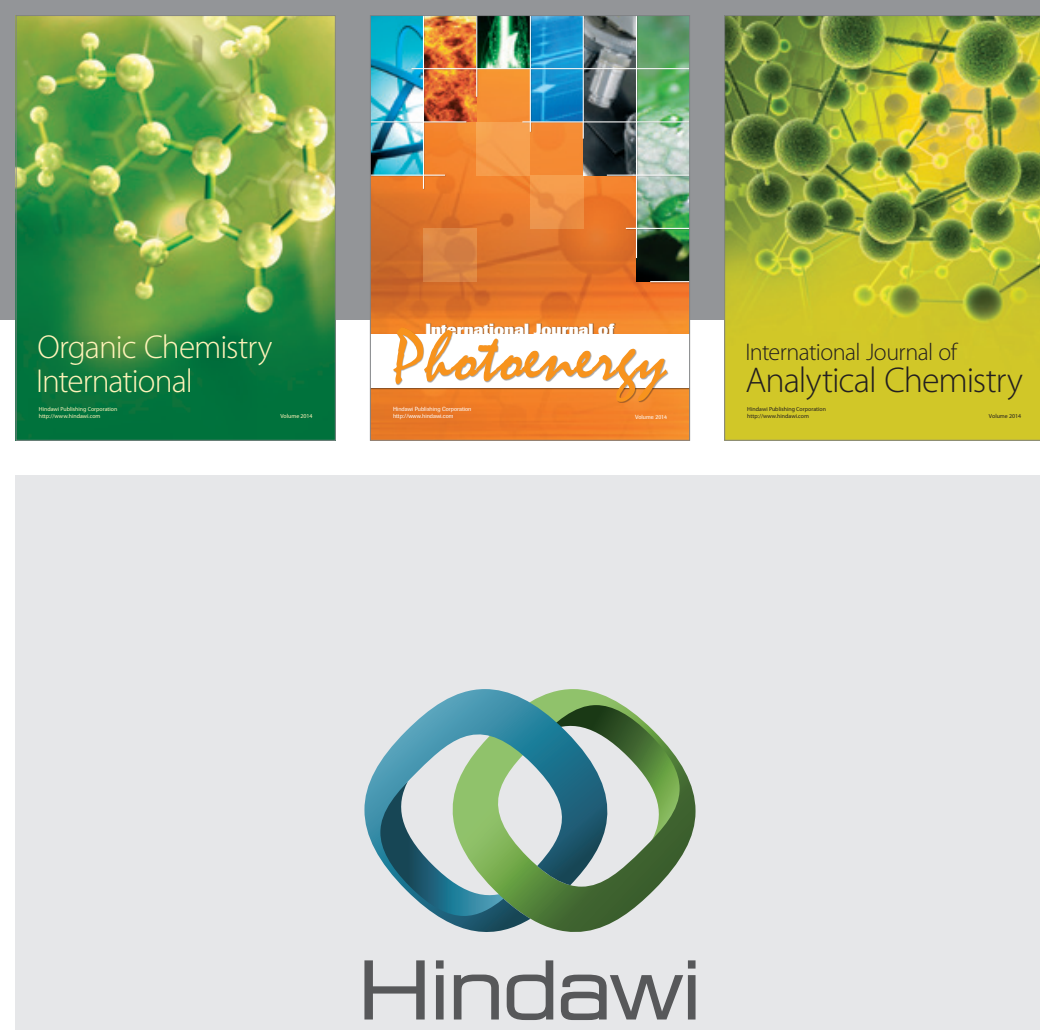

Submit your manuscripts at

http://www.hindawi.com
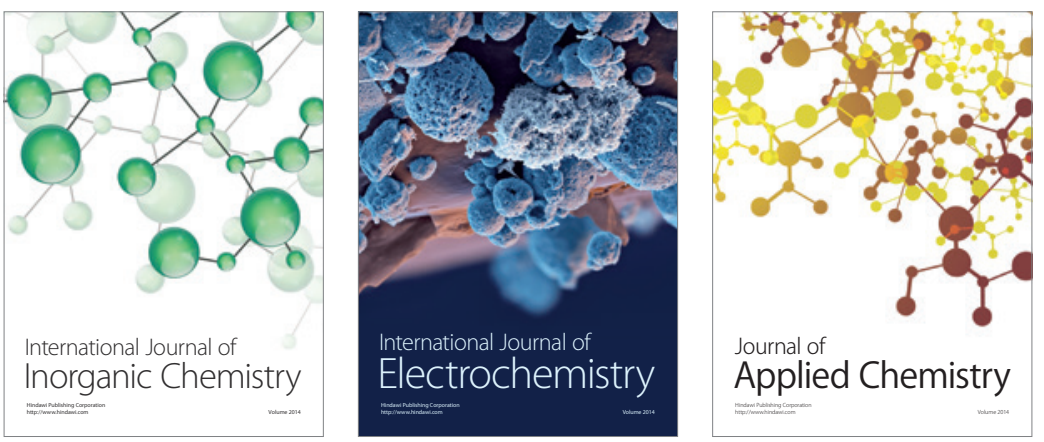

Journal of

Applied Chemistry
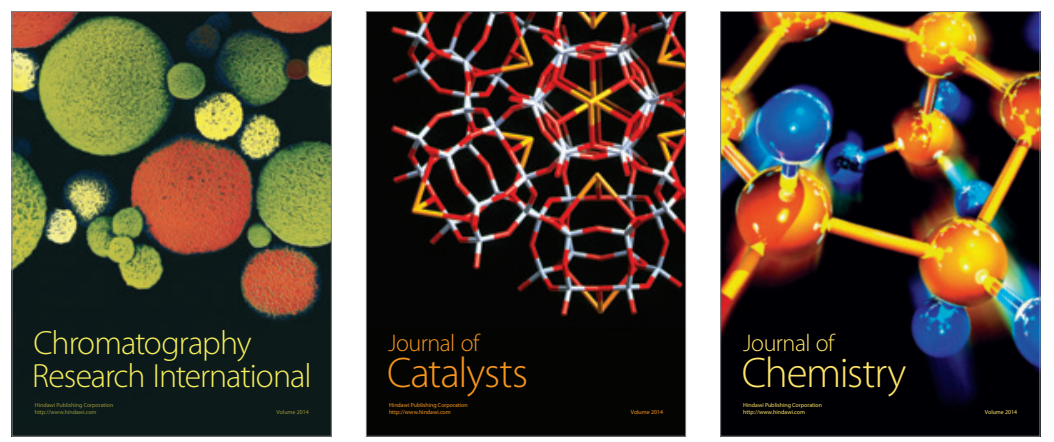
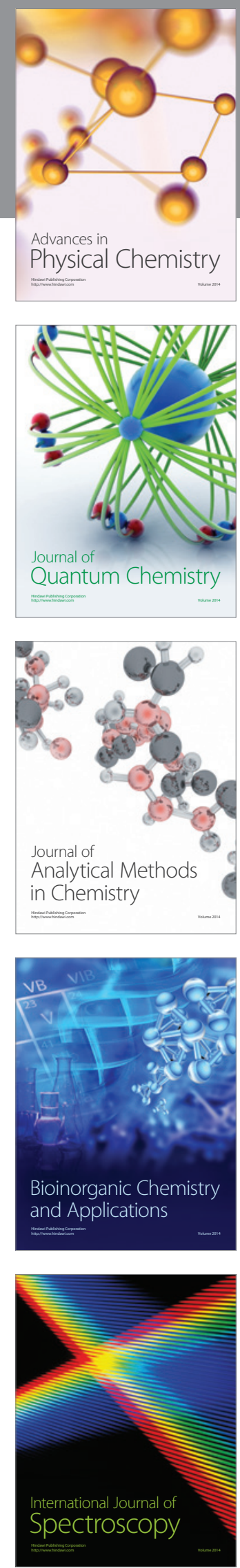